Journal of Manufacturing Engineering, June 2021, Vol. 16, Issue. 2, pp 042 - 047

\title{
MEASUREMENTS OF ALUMINUM-ANNEALED PYROLYTIC GRAPHITE COMPOSITE BASEPLATES WITH IMPROVED THERMAL CONDUCTIVITY
}

\author{
*BIAN Yan-fei, SHI Jian-zhou, XIE Ming-jun and CAI Meng
}

The $54^{\text {th }}$ Research Institute of China Electronics Technology Group Corporation, Shijiazhuang -050081, China

\begin{abstract}
Annealed pyrolytic graphite (APG) is a material with thermal conductivity of about 1500 $\mathrm{W} /(\mathrm{m} \cdot \mathrm{K})$. This property may enable the usage of APG's thermal potential to develop highly thermally conductive composites for devices requiring effective thermal management. In this paper, APG has been encapsulated in aluminum by brazing, and the thermal properties of Al-APG composite baseplates were measured. The results show that the thermal conductivity of the Al-APG composite baseplates is about $620 \mathrm{~W} /(\mathrm{m} \cdot \mathrm{K})$, which is four times higher than the pure aluminum plate $(152$ $\mathrm{W} /(\mathrm{m} \cdot \mathrm{K}))$.
\end{abstract}

Keywords: Thermal management, Annealed pyrolytic graphite, Heat sink, Thermal conductivity and Composite baseplates

\section{Introduction}

The capability to efficiently transfer the heat away from high-powered electronic devices is an ongoing challenge. More than ever, the aluminium or copper heat spreaders seem less suitable for maintaining the component sensitive temperature below manufacturer operating limits. Emerging materials, such as annealed pyrolytic graphite (APG), have proposed a new alternative to conventional solid conduction without the gravity dependence of a heat-pipe solution [1].

Annealed pyrolytic graphite (APG), which contains millions of highly oriented stacked graphene planes, exhibits excellent in-plane thermal conductivity $(>1500 \mathrm{~W} / \mathrm{m} \cdot \mathrm{K})$ and very low density $\left(2.25 \mathrm{~g} / \mathrm{cm}^{3}\right)$. APG is an advanced thermal management material serving military and aerospace industries[2]. APG-metal composites can simultaneously achieve high thermal conductivity from the APG core and high mechanical strength from the metal shell. In these decades, metal matrix composites have attracted much attention because they offer a unique balance of physical and mechanical properties[3].

In this research, APG has been encapsulated in aluminum by using brazing[3-8], and the thermal conductivity of the Al-APG composite baseplates has been measured.

\section{Experimental}

\subsection{Al-APG Composite Baseplate}

Annealed pyrolytic graphite (APG) was supplied by the Institute of Metal Research, the Chinese Academy of Sciences. The APG material is typically sandwiched between a pair of aluminium sheets to compose a robust graphite-based structure. The processing steps include: cutting TPG material and inserting it into the metal cladding, bonding, postbonding machining. Various new bonding processes, including diffusion bonding, epoxy bonding, soldering, and brazing, have been developed to encapsulate TPG material into the metal casing. APG has been encapsulated in aluminum in this research by using brazing proposed by reference [3]. The size of the AlAPG composite baseplate is $186.87 \mathrm{~mm} \times 44.45 \mathrm{~mm} \times 4.00 \mathrm{~mm}$, and the mass is $85.3 \mathrm{~g}$ (Figure 1).

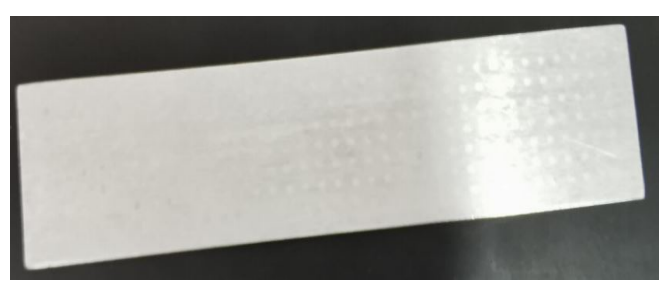

Fig. 1 Al-APG composite baseplate 


\subsection{Test Principle and Device}

According to Fourier's law: $q=-k A d T / d x$, the thermal conductivity $k$ can be obtained by measuring the heat flux density and temperature gradient. Two thick film resistors are pasted on one end of the composite plate with thermal conductive silicone grease, and the other end is attached with a cold plate, as shown in Figure 2. Area and resistance of two thick film resistors: $14 \mathrm{~mm} \times 11 \mathrm{~mm}(100 \Omega), 31 \mathrm{~mm} \times 14 \mathrm{~mm}(34 \Omega)$. After calculation and verification, as shown in Table 1, under the same voltage (assumed to be $20 \mathrm{~V}$ ), the difference in heat flux density between the two plates is $4.1 \%$, which is less than $5 \%$.

Table 1 Working condition of two resistors at $20 \mathrm{~V}$

\begin{tabular}{c|c|c|c|c|c}
\hline $\begin{array}{c}\text { Size } \\
(\mathbf{m m})\end{array}$ & $\begin{array}{c}\text { Area } \\
\left(\mathbf{m m}^{\mathbf{2}}\right)\end{array}$ & $\begin{array}{c}\text { Resist } \\
\text { ance } \\
(\boldsymbol{\Omega})\end{array}$ & $\begin{array}{c}\text { Power } \\
\mathbf{( W )}\end{array}$ & $\begin{array}{c}\text { Heat } \\
\text { flow } \\
\mathbf{d e n s i t y} \\
\left(\mathbf{W} / \mathbf{c m}^{\mathbf{2}}\right)\end{array}$ & $\begin{array}{c}\text { Percen } \\
\text { tage } \\
\text { error }\end{array}$ \\
\hline $11 \times 14$ & 154 & 100 & 4.00 & 259.74 & $4.1 \%$ \\
$31 \times 14$ & 434 & 34 & 11.76 & 270.97 & \\
\hline
\end{tabular}

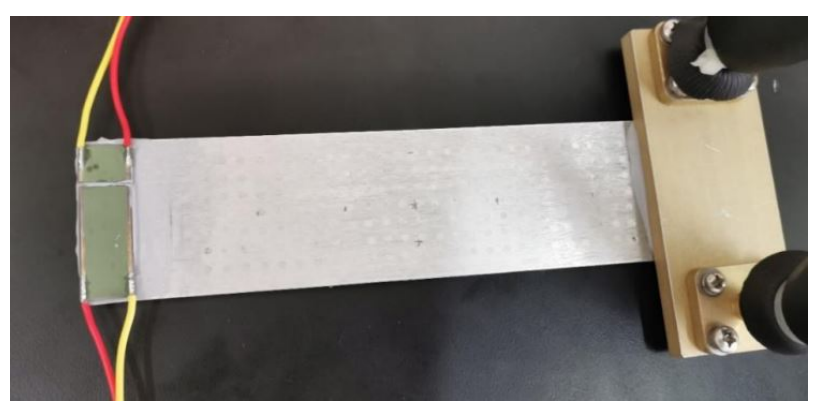

Fig. 2 Distribution of heat and cold sources

In this experiment, a T-type thermocouple was used for temperature measurement, and an Agilent 34970A acquisition instrument was used for temperature acquisition. The schematic diagram of the temperature measurement position is shown in Figure 3. In order to avoid the influence of non-uniformity temperature on the heat source side, the first temperature measuring point is far away from the thick film resistors. The thermocouples of the temperature measurement positions on both sides are numbered 1 6 and 7 12, respectively. For the convenience of comparison, the former is the $\mathrm{A}$-side, the latter is the $\mathrm{B}$ side, and the serial numbers are $\mathrm{A} 1 \sim \mathrm{A} 6$ and $\mathrm{B} 1 \sim \mathrm{B} 6$. During the test, the whole body was wrapped with insulation material, as shown in Figure 4.

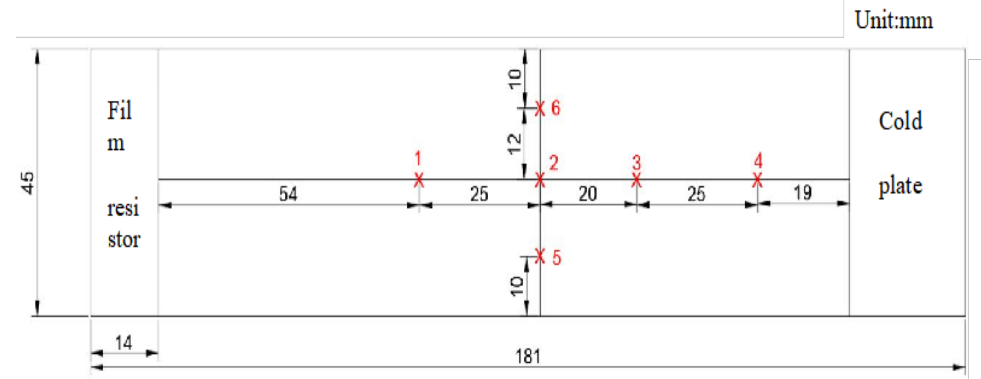

Fig. 3 The temperature measurement position

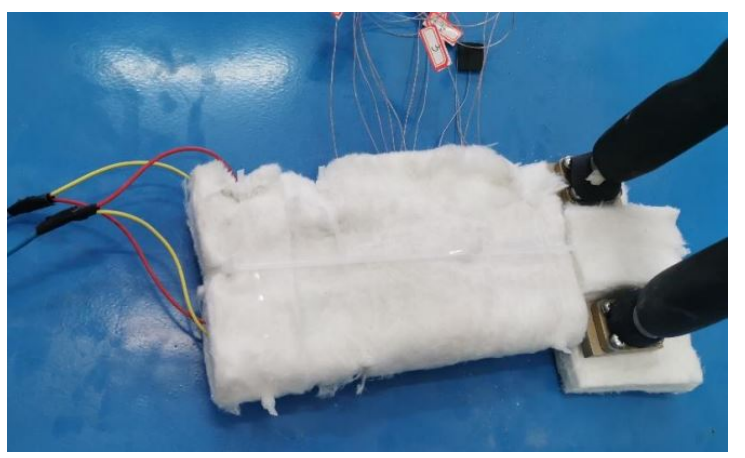

Fig. 4 The whole body was wrapped with insulation material

According to $q=-k A d T / d x$, the temperature of points $1 \sim 4$ on both sides of $A$ and $B$ to the distance are fitted respectively, and the slope $\mathrm{m}$ is used to solve. Let $m=-d T / d x$, the thermal conductivity can be calculated by the following formula:

$$
k=\frac{q}{m A}=\frac{P}{m A}=\frac{U I}{m A}
$$

Where, $\mathrm{U}$ is the voltage at both ends of the resistor, unit $\Omega$; I is the current, unit A; A is the heat transfer area along the length, unit $\mathrm{m}^{2} ; \mathrm{m}$ is the slope, unit $\mathrm{K} / \mathrm{m}$.

\subsection{Experimental Steps}

1. The heat source and the cold source are on the same side;

2. The heat source and the cold source are on the opposite side.

\section{Results and Discussion}

\subsection{Heat and cold sources are on the same side} 3.1.1Thermal conductivity

In this paper, the area of the Al-APG composite baseplate is $1.78 \times 10^{-4} \mathrm{~m}^{2}$. Figure 5 shows the temperatures at points 1 to 4 and their fitting straight lines. The temperature at point 4 is the lowest, and the 
temperature at point 1 is the highest. It can be seen from the figure that the temperature has an excellent linear relationship along the length direction, and the temperature difference between A and B surface is small in each case. When the heat flux density is high, the temperature of the $\mathrm{B}$ side is higher than that of the corresponding point on the A-side, which may be due to the influence of the cold source on the A-side. The next step is to do the experiment with the heat source on the A-side and the cold source on the $\mathrm{B}$ side for comparison.

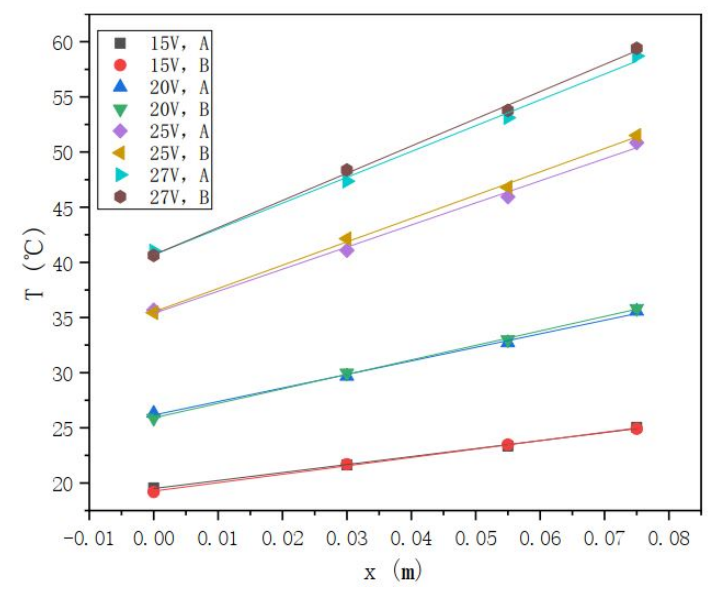

Fig. 5 Data and fitting line of 1-4 points of the AlAPG composite baseplate

The thermal conductivity of each surface in each case will be calculated as shown in Table 2 .

Table 2 Calculation of thermal conductivity of composite baseplate

\begin{tabular}{|c|c|c|c|c|c|}
\hline $\begin{array}{l}3 \\
5 \\
0 \\
0 \\
\pm 0 \\
0 \\
0\end{array}$ & 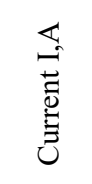 & $\begin{array}{l}3 \\
0 \\
\overline{0} \\
\vdots \\
0 \\
0\end{array}$ & $\frac{\theta}{0}$ & 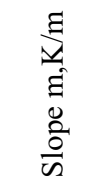 & 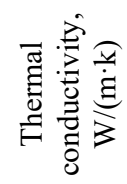 \\
\hline 15 & 0.586 & 8.79 & $\begin{array}{l}\text { A } \\
B\end{array}$ & $\begin{array}{l}72.40 \\
76.20\end{array}$ & $\begin{array}{l}682.07 \\
648.02\end{array}$ \\
\hline 20 & 0.783 & 15.66 & $\begin{array}{l}\text { A } \\
B\end{array}$ & $\begin{array}{l}122.76 \\
131.34\end{array}$ & $\begin{array}{l}716.67 \\
669.82\end{array}$ \\
\hline 25 & 0.984 & 24.60 & $\begin{array}{l}\text { A } \\
\text { B }\end{array}$ & $\begin{array}{l}200.29 \\
211.45\end{array}$ & $\begin{array}{l}690.01 \\
653.61\end{array}$ \\
\hline 27 & 1.065 & 28.76 & $\begin{array}{l}\text { A } \\
\text { B }\end{array}$ & $\begin{array}{l}233.93 \\
246.63\end{array}$ & $\begin{array}{l}690.58 \\
655.00\end{array}$ \\
\hline
\end{tabular}

It can be seen from the table that the thermal conductivity on the B side at $15 \mathrm{~V}$ is $648.02 \mathrm{~W} /(\mathrm{m} \bullet \mathrm{K})$, which is close to $650 \mathrm{~W} /(\mathrm{m} \cdot \mathrm{K})$, and the other test values are all greater than $650 \mathrm{~W} /(\mathrm{m} \cdot \mathrm{K})$. The thermal conductivity calculated on the B side is less than the value on the A-side. Assuming that part of the heat will be lost during the heating process, the measured power will be greater than the actual value. The greater the heating power, the more heat will be lost, and the greater the measured thermal conductivity. However, this rule did not appear in this experiment. Therefore, it shows that the heat insulation effect of this experiment is better, and the heat loss is slight.

In order to obtain the influence caused by insufficient thermal insulation, the thermal conductivity of aluminium 6061 (T6) with the same size as the composite baseplate has been tested by the same method, as shown in Fig 6. Table 3 shows the thermal conductivity calculated by the temperature measured on two surfaces under different power.

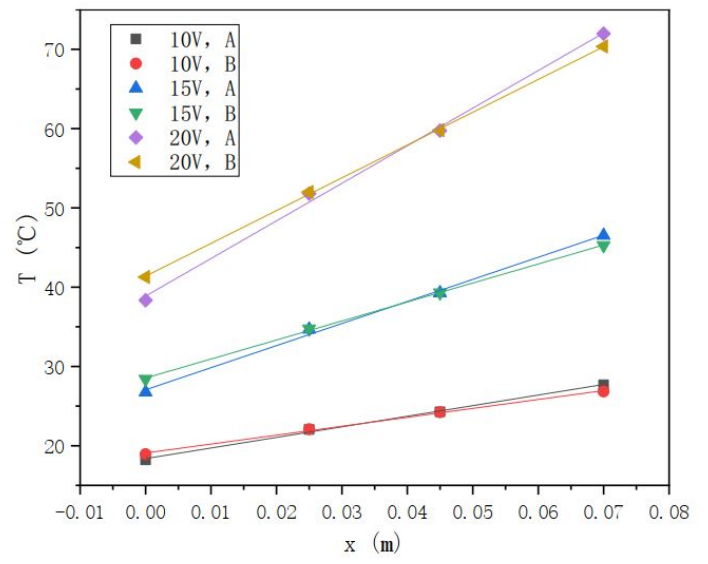

Fig. 6 Data and fitting line of 1 4 points of aluminum plate (heat and cold sources in the same plane)

Table 3 Thermal conductivity of aluminum plate (heat and cold sources are in the same plane)

\begin{tabular}{|c|c|c|c|c|c|}
\hline 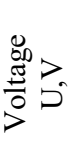 & 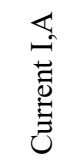 & $\begin{array}{l}3 \\
0 \\
\overline{0} \\
0 \\
0 \\
0\end{array}$ & $\frac{0}{\pi}$ & $\frac{\tilde{O}}{\tilde{D}} \frac{\Xi}{\Xi}$ & 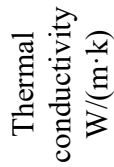 \\
\hline 10 & 0.390 & 3.90 & $\begin{array}{l}\text { A } \\
\text { B }\end{array}$ & $\begin{array}{l}133.570 \\
12.434\end{array}$ & $\begin{array}{l}167.81 \\
19935\end{array}$ \\
\hline 15 & 0.586 & 8.79 & $\begin{array}{l}\text { A } \\
\text { B }\end{array}$ & $\begin{array}{l}278.600 \\
239.770\end{array}$ & $\begin{array}{l}181.33 \\
210.69\end{array}$ \\
\hline 20 & 0.783 & 15.66 & $\begin{array}{l}\text { A } \\
\text { B }\end{array}$ & $\begin{array}{l}474.089 \\
413.474\end{array}$ & $\begin{array}{l}189.84 \\
217.67\end{array}$ \\
\hline
\end{tabular}

From Figure 6, it can be seen that when it is close to the heat source, the temperature of the A surface is higher; when it is close to the cold source, the temperature of the B surface is higher. This is due to the non-uniform temperature of the cross-section along the length direction caused by the low thermal conductivity. Compared with Fig 5, it is found that this influence has 
less influence on the Al-APG composite baseplate. It may be due to the high thermal conductivity of the AlAPG composite baseplate, which can transfer heat between $\mathrm{A}$ and $\mathrm{B}$ surfaces faster.

Table 3 shows the calculated thermal conductivity of different sides of the aluminum plate at various powers. It can be seen that the value calculated by the $B$ surface is $30 \mathrm{~W} /(\mathrm{m} \cdot \mathrm{k})$ greater than that of the $A$ surface. The greater the power, the greater the calculated thermal conductivity. The calculation results of the three groups are quite different. The reason may be that the aluminium plate's thermal conductivity is relatively small, which leads to a higher temperature at the heat source and more heat loss, and the measured value is larger than the actual value.

\subsubsection{Temperature non-uniformity}

In order to understand the uniformity of heat transfer along the length direction, three thermocouples are respectively arranged on both sides of a certain section in the middle, which are No.2, No.5 and No.6 points on the surface. The temperature of each point under different voltages is shown in Fig 7. It can be seen from this figure that the temperature at point 5 is the highest, and the temperature at point 6 is the lowest. The larger the heating power, the larger the temperature difference of the two surfaces. For a certain side, For the whole section, the absolute temperature difference is within $3^{\circ} \mathrm{C}$, and the smaller the heating power, the smaller the temperature difference.

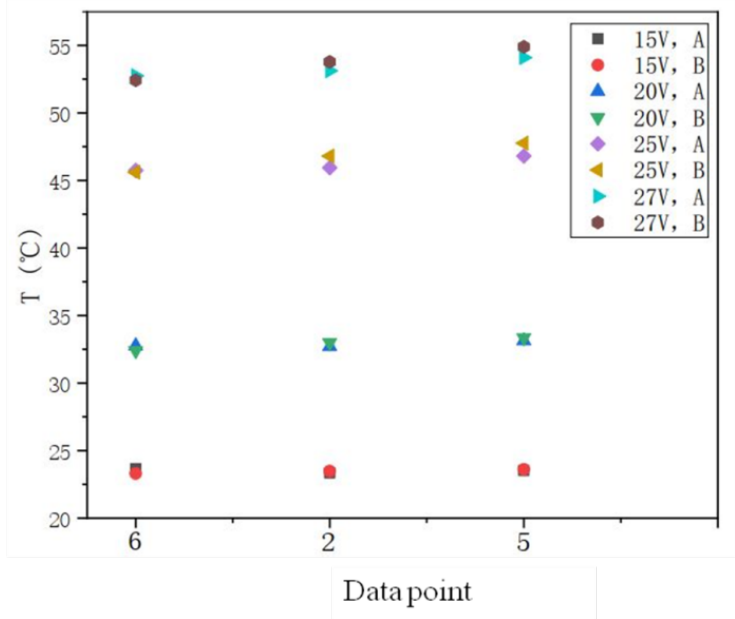

Fig. 7 Temperature distribution of a specific section of composite plate

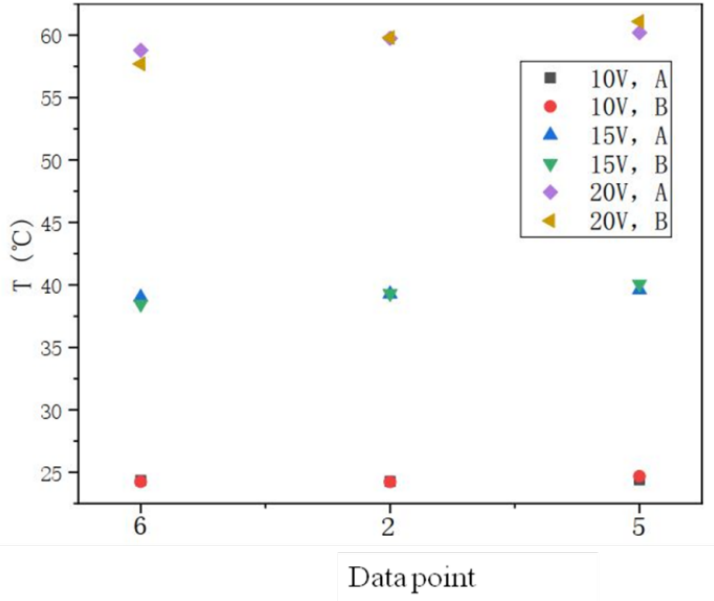

Fig. 8 The temperature of a specific cross-section of the aluminium plate (heat and cold sources are in the same plane)

The temperature change trend of the aluminium plate at this section is the same as that of the composite plate, but the maximum temperature difference is $3.4^{\circ} \mathrm{C}$, which is larger than that of the composite plate.

\subsection{Heat and cold sources are on the opposite} side

The heat source is still attached to the A-side, but the cold source is attached to the B side, as shown in Fig 9. The test method and test points are the same as before. The stable temperature of each surface and the fitting straight line are shown in Fig 10, and the slope of the fitting straight line and the thermal conductivity obtained are shown in Table 4

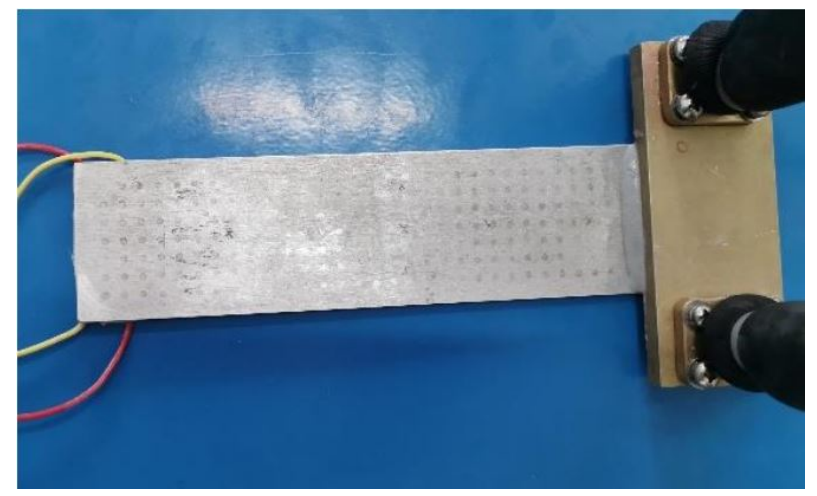

Fig. 9 Heat and cold sources are in the opposite plane 
Journal of Manufacturing Engineering, June 2021, Vol. 16, Issue. 2, pp 042 - 047

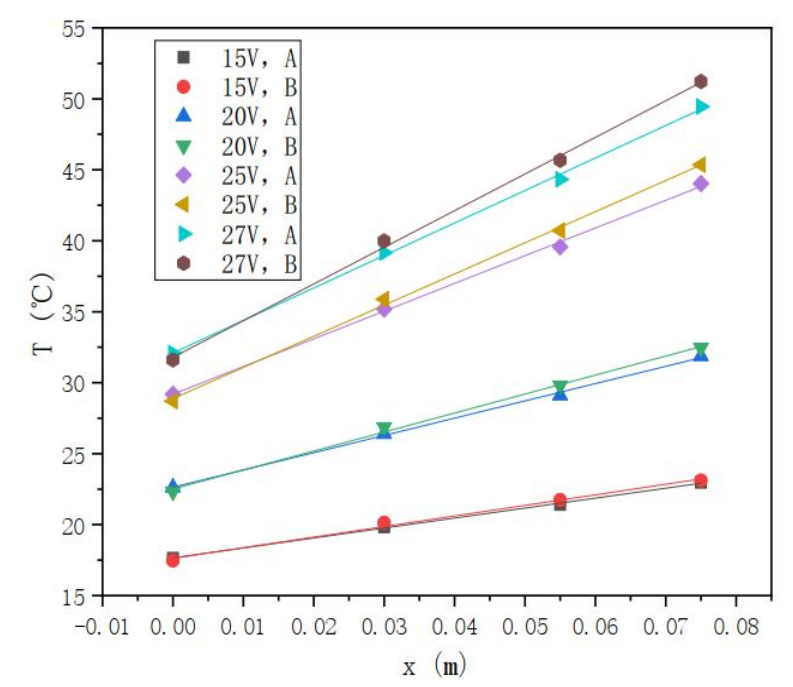

Fig. 10 Data and fitting line of 1-4 points of test plate (Heat and cold sources are in the opposite plane)

Table 4 Thermal conductivity of the test board (Heat and cold sources are in the opposite plane)

\begin{tabular}{|c|c|c|c|c|c|}
\hline 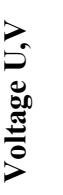 & & $\begin{array}{l}3 \\
\text { a } \\
\dot{0} \\
\dot{0} \\
0\end{array}$ & : & 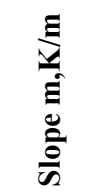 & 晃 \\
\hline 15 & 0.591 & 8.865 & $\begin{array}{l}\mathrm{A} \\
\mathrm{B}\end{array}$ & $\begin{array}{l}70.18 \\
74.51\end{array}$ & $\begin{array}{l}709.67 \\
668.40\end{array}$ \\
\hline 20 & 0.789 & 15.78 & $\begin{array}{l}\text { A } \\
\text { B }\end{array}$ & $\begin{array}{l}121.70 \\
133.75\end{array}$ & $\begin{array}{l}728.44 \\
662.80\end{array}$ \\
\hline 25 & 0.987 & $\begin{array}{c}24.67 \\
5\end{array}$ & $\begin{array}{l}\text { A } \\
\text { B }\end{array}$ & $\begin{array}{l}195.23 \\
219.50\end{array}$ & $\begin{array}{l}710.06 \\
631.53\end{array}$ \\
\hline 27 & 1.067 & $\begin{array}{c}28.80 \\
9\end{array}$ & $\begin{array}{l}\text { A } \\
\text { B }\end{array}$ & $\begin{array}{l}228.91 \\
258.18\end{array}$ & $\begin{array}{l}707.05 \\
626.89\end{array}$ \\
\hline
\end{tabular}

It can be seen from Table 4 that the thermal conductivity measured on the $\mathrm{B}$ side is also lower than that on the A-side, and there are two values below 650 $\mathrm{W} /(\mathrm{m} \cdot \mathrm{K})$. For aluminum plates, the different surfaces of heat and cold sources are tested, and the experimental results are shown in Table 5. The calculation result is the same as the heat and cold source of the aluminum plate. But the measured temperature, as shown in Fig 11 , the temperature of the B surface is almost always greater than the temperature of the A surface.
Table 5 Thermal conductivity of aluminum plate

\begin{tabular}{|c|c|c|c|c|c|}
\hline 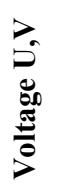 & 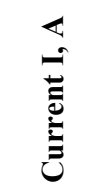 & $\begin{array}{l}3 \\
\dot{0} \\
\dot{0} \\
\dot{0}\end{array}$ & $\stackrel{0}{0}$ & 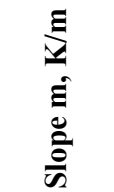 & 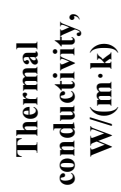 \\
\hline 10 & 0.390 & 3.90 & $\begin{array}{l}\text { A } \\
\text { B }\end{array}$ & $\begin{array}{l}137.18 \\
120.07\end{array}$ & $\begin{array}{l}163.38 \\
186.67\end{array}$ \\
\hline 15 & 0.585 & 8.78 & $\begin{array}{l}\text { A } \\
\text { B }\end{array}$ & $\begin{array}{l}286.76 \\
254.59\end{array}$ & $\begin{array}{l}175.87 \\
198.09\end{array}$ \\
\hline 20 & 0.781 & 15.62 & $\begin{array}{l}\mathrm{A} \\
\mathrm{B}\end{array}$ & $\begin{array}{l}489.71 \\
437.06 \\
\end{array}$ & $\begin{array}{l}183.31 \\
205.40 \\
\end{array}$ \\
\hline
\end{tabular}

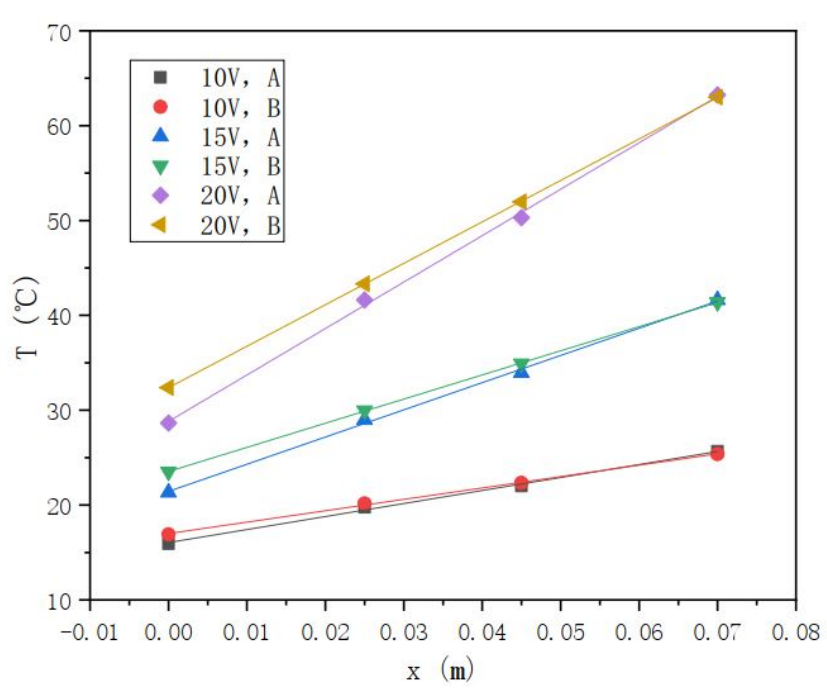

Fig. 11 Data of 1 4 points of aluminum plate and fitting straight line (AB plane)

In order to clarify the measurement error in this experiment, the thermal conductivity of aluminum plate is measured by Hot Disk. The average value of the four sets of values is $152.3 \mathrm{~W} /(\mathrm{m} \cdot \mathrm{K})$. From the experimental device, the smaller the heating power, the more accurate the experimental results. For the test results of aluminum plate in this experiment at the lowest power (the heat and cold sources are in the same plane), the accurate value measured by the experimental instrument is larger than $11 \%$. In this paper, this error is used to estimate the true thermal conductivity of composite plate at the same temperature according to the experimental values. 


\section{Conclusions}

When the heat and cold sources are on the same side and on different sides (the heat sources are all on side A), the thermal conductivity of the former calculated by the A-side is smaller than the results obtained by the latter, but the difference between the results obtained by the two sides of the former is smaller than the latter. Under the same heat flux density, when the heat and cold sources are on the same side, the temperature is relatively high.

Under the same power, the surface temperature of the aluminum plate is higher than that of the composite plate. When the applied voltage of the thick film resistor on the aluminium plate is $10 \mathrm{~V}$ and the composite plate is $15 \mathrm{~V}$, the temperature of the two plates is relatively close, and the heat leakage is relatively close. Therefore, the two sets of data and the actual thermal conductivity of the aluminum plate can be used to calculate the actual thermal conductivity of the composite plate. The results show that the thermal conductivity of the Al-APG composite baseplates is about $620 \mathrm{~W} /(\mathrm{m} \cdot \mathrm{K})$, which is four times higher than the pure aluminium plate $(152 \mathrm{~W} /(\mathrm{m} \cdot \mathrm{K}))$.

\section{References}

1. Nhat Minh Nguyen, Eric Monier-Vinard, et al. (2017), Practical analytical steady-state temperature solution for annealed pyrolytic graphite heat spreader, International Journal of Numerical Methods for Heat \& Fluid Flow, vol.27, no.1, pp:174-188.

2. Wei Fan, Eelco Galestien, et al. (2016), Doubling the Output of Automotive LED Headlight with Efficient Cooling Using Thermal Pyrolytic Graphite, 15th IEEE ITHERM Conference, 180-184.

3. Zechao Tao, Quangui Guo, et al. (2011), The wettability and interface thermal resistance of copper/graphite system with an addition of chromium, Materials Chemistry and Physics, 128, addition $228-232$.

4. Z.B.Chen, H.Bian, et al. (2018), Surface modification on wetting and vacuum brazing behaviour of graphite using $\mathrm{Ag} / \mathrm{Cu}$ filler metal, Surface \& Coatings Technology, 348, 104-110.

5. Jinliang Song, Ouangui Guo, et al. (2011), $\mathrm{Mo}_{2} \mathrm{C}$ intermediate layers for graphite-Cu system using the molten salt method, Fusion Engineering and Design, 86, 2965-2970.

6. Zhenhua Yi, Liping Ran, et al. (2019), Differences in microstructure and properties of $\mathrm{C} / \mathrm{C}$ composites brazed with $\mathrm{Ag}-\mathrm{Cu}-\mathrm{Ti}$ and $\mathrm{Ni}-\mathrm{Cr}-\mathrm{P}-\mathrm{Ti}$ pasty brazing filler, Vacuum, 168, 108804.

7. Bin Jiang, Huatao Wang, et al. (2016), Copper-graphite-copper sandwich: superior heat spreader with excellent heat-dissipation ability and good weldability, RSC Advances, 6, 25128-25136.

8. Yangwu Mao, Sheng Wang, et al. (2016), Brazing of graphite to $\mathrm{Cu}$ with $\mathrm{Cu}_{50 \mathrm{TiH}}+\mathrm{C}$ composite filler, J Mater Sci, 51, 16711679. 